\title{
Peripheral Vascular Complications After Conventional and Complex Percutaneous Coronary Interventional Procedures
}

\author{
David W. M. Muller, MBBS, Kenath J. Shamir, MD, Stephen G. Ellis, MD, and Eric J. Topol, MD
}

\begin{abstract}
To determine whether complex cardlovascular interventional procedures (including coronary stent implantalion, directional atherectomy, aortic valvuloplasty, and the use of an intraaortic balloon pump or cardlopulmonary bypass support) are associated with an increased fikelihood of vascular access site complications, 2,400 consecutive car. dlac catheterization procedures were prospectiveIy screened over a 12-month study period. Complicatlons occurred in 35 patients after 39 proce-
\end{abstract} dures (1.6\%) and included the need for vascular surgical repair (17 patients), blood transfusion (28 patients) and systemic antibiotic therapy (7 patients). The incidence of complications after 1,519 diagnostic studies was $0.6 \%$, after 698 conventional coronary balloon angloplasties 2.6\%, and after 183 complex interventions $6.0 \%$ (p $<0.0001$ ); $43 \%$ of the complications occurred after procedures of $>2$ hours' duration and $14 \%$ occurred in patients in whom arterial sheaths remained in situ for $>\mathbf{2 4}$ hours. Detailed demographic and procedural characteristics were compared between the 35 patients with vascular complications and 150 patients randomly drawn from a computerized database of the uncomplicated procedures performed during the screening period. By univariate analysis with correction for multiple comparisons, variables predicting the likellhood of vascular complications includeds periprocedural use of heparin $(p<0.001)$ or fibrinolytic therapy ( $<0.001)$, arterial sheath size $\geq 8$ Fr ( $p$ $<0.001$ ), patient age $\geq 65$ years $(p=0.01)$, and the presence of peripheral vascular disease $(p=0.03)$.

The results of this study suggest that the overall incidence of access site complications is low but increases with the use of complex cardiovascular interventional procedures. Further refinements in the caliber of the new devices, vigilant monitoring of adfunctive anticoagulant therapy, and careful patient selection may reduce the morbidity and increase the safety of these procedures. (Am J Cardiol 1992;69:63-68)

From the Division of Cardiology, Department of Internal Medicine, University of Michigan Medical Center, Ann Arbor, Michigan. Manuscript received June 27, 1991; revised manuscript received and accepted August 6, 1991.

Address for reprints: David W. M. Muller, MBBS, Division of Cardiology, B1 F245, University of Michigan Medical Center, 1500 East Medical Center Drive, Ann Arbor, Michigan 48109-0022.
S ince the advent of diagnostic cardiac catheterization $>25$ years ago, the complexity of diagnostic and therapeutic coronary angiographic procedures has increased considerably. This has resulted, in part, from an expansion of the indications for percutaneous coronary intervention to include older and more hemodynamically unstable patients, and patients with more extensive coronary and peripheral vascular disease. ${ }^{1-4}$ In addition, the introduction of a variety of new devices for the treatment of coronary arterial disease, including atherectomy catheters, metallic stents and circulatory support devices, has necessitated the use of both large caliber guiding catheters and arterial sheaths, and intensive periprocedural anticoagulant and fibrinolytic therapy. ${ }^{5-7}$ The hazards associated with the use of these new devices include a potentially greater risk of arterial injury at the access site. Previous studies have reported the incidence of arterial complications after diagnostic cardiac catheterization ${ }^{1-2,8-11}$ and percutaneous transluminal coronary angioplasty (PTCA), ${ }^{3,12-15}$ but the incidence of peripheral vascular complications after more complex interventional procedures has not been systematically evaluated. The aims of this study, therefore, were (1) to characterize and to compare the risks of peripheral vascular injury after diagnostic cardiac catheterization, conventional PTCA, and complex coronary interventional procedures; and (2) to identify clinical and procedural factors that predict the likelihood of these complications.

\section{METHODS}

Patient selection and clirical assessments All patients undergoing diagnostic or therapeutic cardiac catheterization at the University of Michigan Medical Center were prospectively evaluated over a 12-month study period. Each patient was interviewed and examined by a physician or physician's assistant immediately before the procedure. The clinical variables recorded included patient age, sex, height and weight, presenting symptoms, risk factors for arteriosclerotic disease, and the presence or absence of clinically detectable peripheral vascular disease. The procedural parameters recorded included the type of catheterization procedure performed, the size of the arterial and venous sheaths, the peri- or postprocedural use of antiplatelet, anticoagulant or fibrinolytic therapy, the duration of the procedure, the length of time from procedure completion until sheath removal, and the duration of bedrest after sheath removal. Patients undergoing outpatient diagnostic procedures were examined for evidence of access site complications immediately before discharge and were then interviewed by telephone 48 to 72 hours later. $\mathrm{Pa}$ - 
tients remaining in the hospital were examined daily for the duration of the hospital stay. When vascular injury was suspected, duplex color flow Doppler imaging was performed as previously described, ${ }^{16}$ and a vascular surgical opinion was obtained. All complications were prospectively recorded, and the subsequent course of each patient in this group was then followed to document the need for and timing of surgical repair, and the nature of the arterial injury as identified at the time of surgery. Details of the vascular surgical management of the peripheral vascular complications of cardiac catheterization procedures at our institution have been previously published. ${ }^{17}$

Procedural details: Ninety-nine percent of the cardiac catheterization procedures during the study period were performed from a percutaneous femoral arterial or venous approach; the remainder were performed from the brachial approach. Arterial punctures for diagnostic procedures were performed predominantly by junior cardiology fellows; those for interventional procedures were performed by senior cardiology fellows or by 1 of 6 attending physicians. Diagnostic procedures were performed through 6,7 or 8Fr arterial sheaths. Heparin was not administered routinely during elective procedures; in stable patients, intravenous heparin infusions were discontinued $\geq 4$ hours before arterial needle puncture. In patients undergoing emergency cardiac catheterization soon after the administration of thrombolytic therapy and heparin for acute myocardial infarction, the sheaths remained in situ after the completion of the procedure until the fibrinogen level had risen to $\geq 150$ $\mathrm{mg} / \mathrm{dl}$ and the activated partial thromboplastin time had returned to the normal range. All patients undergoing elective PTCA were pretreated with oral aspirin $(325 \mathrm{mg} /$ day) and received intraprocedural heparin $(10,000$ to $15,000 \mathrm{U}$ intravenous bolus, then $5,000 \mathrm{U}$ intravenously each hour). Therapy with heparin was not continued after uncomplicated procedures, and the sheaths ( 7 or $8 \mathrm{Fr}$ ) were removed approximately 4 hours after the last heparin bolus. Patients with suboptimal angiographic results were treated overnight with an infusion of intravenous heparin (approximately 1,000 U/ hour) and had their sheaths removed the following morning, 4 hours after discontinuation of heparin. Procedural details of the complex procedures have been previously described..$^{5-7}$ In brief, coronary stents were placed through 8,9 or $10 \mathrm{Fr}$ guiding catheters and arterial sheaths, coronary atherectomy was performed through $11 \mathrm{Fr}$ guiding catheters, intraaortic balloon pumps were placed through 9.5 or $10.5 \mathrm{Fr}$ sheaths, aortic balloon valvuloplasty procedures were performed through 12 or $14 \mathrm{Fr}$ sheaths, and percutaneous cardiopulmonary support was instituted through 18 or $21 \mathrm{Fr}$ arterial and venous sheaths. The anticoagulation regimen for most complex interventions was similar to that described for conventional PTCA. Patients in whom coronary stents were implanted were pretreated with oral persantine and intravenous dextran (in addition to oral aspirin), and continued with infusion of heparin at therapeutic concentrations until oral anticoagulation with coumadin was established. Before sheath removal, the heparin infusion rate was reduced to $400 \mathrm{U} /$ hour for a period of approximately 4 hours. The rate was then increased to the therapeutic rate 1 hour after sheath removal and the achievement of secure hemostasis. In patients in whom cardiopulmonary support was instituted, sufficient heparin was given to maintain the activated clotting time $\geq 300$ seconds for the duration of the procedure. After completion of the procedure, sheaths were removed either by elective vascular surgical repair or by removal and prolonged compression after the clotting parameters had returned to normal.

Complications: Access site complications were defined as (1) local or retroperitoneal hemorrhage requiring the transfusion of $\geq 2 \mathrm{U}$ of blood, (2) the need for surgical drainage or nonelective arterial repair of the access site, or (3) local or systemic infection requiring oral or intravenous antibiotic therapy. Patients undergoing elective surgical removal of cardiopulmonary support device sheaths were not included. The cardiac catheterization procedures performed were classified as diagnostic procedures (including right-sided cardiac catheterization, selective coronary angiography, left ventriculography and aortography), conventional coronary balloon angioplasty (including the adjunctive use of intracoronary or systemic fibrinolytic therapy) or complex interventional procedures. The latter classification included aortic balloon valvuloplasty, and the use of new percutaneous coronary revascularization devices (directional coronary atherectomy, endovascular stents or laser ablation catheters), or circulatory support devices (intraaortic balloon counterpulsation or percutaneous cardiopulmonary bypass). Predictive risk factors for peripheral vascular complications were identified by comparing the prevalence of selected clinical variables (patient age, presence of $\geq 3$ risk factors for coronary arterial disease, and the presence of peripheral vascular disease) and procedural variables (arterial sheath size, and use of intraprocedural heparin or periprocedural fibrinolytic therapy) in the group of patients with access site complications and in a group of 150 patients randomly selected from the computerized database of event-free cardiac catheterization procedures.

Statistics: Differences in the incidence of complications between groups were compared using chi-square analysis. Univariate chi-square analysis with a Bonferroni correction for multiple comparisons was performed to identify individual clinical and procedural factors predicting the likelihood of arterial complications. A 2tailed probability value $<0.05$ was considered statistically significant.

\section{RESULTS}

Access sile complications: During the study period, 2,400 consecutive elective or emergency cardiac catheterization procedures were performed. These procedures included, 1,519 diagnostic procedures, 698 conventional coronary balloon angioplasties and 183 complex interventional procedures. The complex procedures included 69 coronary atherectomies, 25 coronary stent implantations, 34 aortic valvuloplasties, and the use of an intraaortic balloon pump in 45 patients and percutaneous 


\begin{tabular}{|cc|}
\hline $\begin{array}{l}\text { TABLE I Peripheral Vascular Complications: All } \\
\text { Catheterization Procedures }\end{array}$ \\
\hline \multicolumn{1}{|c|}{ Complications } & Number (\%) \\
\hline Vascular & \\
Pseudoaneurysm & $8(21)$ \\
Laceration & $6(15)$ \\
Arterial occlusion & $3(8)$ \\
Arteriovenous fistula & $3(8)$ \\
Hematoma & $1(3)$ \\
Need for blood transfusion ( $\geq 2 \cup)$ & $14(36)$ \\
With vascular surgery & $14(36)$ \\
Without vascular surgery & $7(18)$ \\
Sepsis & $2(6)$ \\
Death & \\
\hline
\end{tabular}

TABLE II Demographic Variables and Peripheral Vascular Complications

\begin{tabular}{|lcc|}
\hline \multicolumn{1}{|c}{ Variable } & $\begin{array}{c}\text { Complication }(\%) \\
(\mathrm{n}=39)\end{array}$ & $\begin{array}{c}\text { No Complications }(\%) \\
(\mathrm{n}=150)\end{array}$ \\
\hline Age $\geq 65$ years & $20(51)$ & $39(26)$ \\
Men/women & $21 / 18(54 / 46)$ & $105 / 45(70 / 30)$ \\
Systemic hypertension & $22(56)$ & $56(37)$ \\
Diabetes mellitus & $12(31)$ & $56(15)$ \\
Cigarette smoking & $24(62)$ & $75(50)$ \\
Hypercholesterolemia & $22(56)$ & $55(34)$ \\
$\begin{array}{c}\text { Peripheral vascular dis- } \\
\text { ease }\end{array}$ & $11(28)$ & $15(10)$ \\
$\begin{array}{c}\text { Obesity (body mass in- } \\
\left.\text { dex } \geq 28 \mathrm{~kg} / \mathrm{m}^{2}\right)\end{array}$ & $8(21)$ & $65(43)$ \\
\hline
\end{tabular}

cardiopulmonary bypass support in 10 patients. Access site complications were identified in 36 patients (21 men, 15 women) after 39 procedures, each of which was performed using a percutaneous femoral arterial approach. The incidence of complications after diagnostic procedures was $0.6 \%$, after conventional balloon angioplasty $2.6 \%$, and after complex interventional procedures $6.6 \%(\mathrm{p}<0.0001$ ) (Figure 1). Complications occurred in $4 \%$ of patients requiring intraaortic balloon counterpulsation, in $6 \%$ of patients undergoing atherectomy, $6 \%$ after aortic valvuloplasty, $8 \%$ after coronary stent implantation, and $20 \%$ after use of percutaneous cardiopulmonary support.

The complications encountered were predominantly associated with femoral arterial injury that occurred after 21 procedures (Table I). The most frequent injury was a femoral arterial pseudoaneurysm, which was identified by color flow Doppler imaging or at the time of surgery. Five of the 8 pseudoaneurysms were surgically repaired and 3 were treated conservatively. Each of the other vascular complications, including a femoral arterial laceration in 6 patients, arterial occlusion or thromboembolism in 3 patients, and femoral arteriovenous fistulas in 3 patients, required surgical treatment. Overall, surgical repair was required after $0.3 \%$ of diagnostic procedures, $0.7 \%$ of conventional angioplasty procedures and $3.8 \%$ of complex interventions ( $\mathrm{p}<0.0001)$ (Figure 1). Blood transfusion of $\geq 2 \mathrm{U}$ of blood was required after 28 procedures (72\%); 14 of these transfusions were administered to patients requiring vascular surgical repair of the access site and the remainder were

\begin{tabular}{|lccccc|}
\hline TABLE III Univariate Analysis of Risk Factors \\
\hline \multicolumn{1}{c}{ Variable } & $\begin{array}{c}\text { Univariate } \\
\text { Chi-Square }\end{array}$ & $\begin{array}{c}\text { Corrected } \\
\text { p Value }\end{array}$ & $\begin{array}{c}\text { Odds } \\
\text { Ratio }\end{array}$ & $95 \% \mathrm{Cl}$ \\
\hline Artcrial sheath size $\geq 8 \mathrm{Fr}$ & 23.3 & $<0.001$ & 5.0 & 2.3 & 10.6 \\
Thrombolytic therapy & 29.0 & $<0.001$ & 4.9 & $3.2-7.4$ \\
Periprocedural heparin & 20.8 & $<0.001$ & 4.2 & $2.1-8.6$ \\
Age $\geq 65$ years & 9.8 & 0.01 & 2.4 & $1.4-4.1$ \\
Peripheral vascular dis- & 8.2 & 0.03 & 2.4 & $1.4-4.3$ \\
$\quad$ ease & & & & & \\
$\geq 3$ coronary risk factors & 2.3 & 0.06 & 2.3 & $1.3-4.0$ \\
\hline $\mathrm{Cl}=$ confidence interval. & & & & \\
\hline
\end{tabular}

administered to patients with local hemorrhage who were treated nonsurgically. Antibiotic therapy was administered to 7 patients (Table I), each of whom had infection limited to the local access site with no evidence of systemic infection by multiple blood cultures. One patient died from multisystem organ failure after diagnostic cardiac catheterization, and 1 patient died 24 hours after coronary balloon angioplasty from abrupt closure of the dilated right coronary artery. In this series, there were no postprocedural deaths after complex interventional procedures.

Demographle risk factors for vascular complications: When compared with the 150 randomly selected patients without complications, patients with access site complications tended to be older, had a greater prevalence of individual risk factors for atherosclerotic disease and a higher incidence of peripheral vascular disease, but had a lower incidence of obesity (defined as a body mass index $\geq 28 \mathrm{~kg} / \mathrm{m}^{2}$, where body mass index = weight $/$ height $^{2}$ ) (Table II). By univariate analysis after correction for multiple comparisons, patient age $\geq 65$ years and the presence of peripheral vascular disease remained statistically significant risk factors $(p=0.01$ and $p=0.03$, respectively) (Table III).

Procedural riak factors for vascular complications: The strongest procedural predictors of the likelihood of peripheral vascular complications were the use of large caliber introducing sheaths and the use of periprocedural anticoagulant and fibrinolytic therapy (Tables III

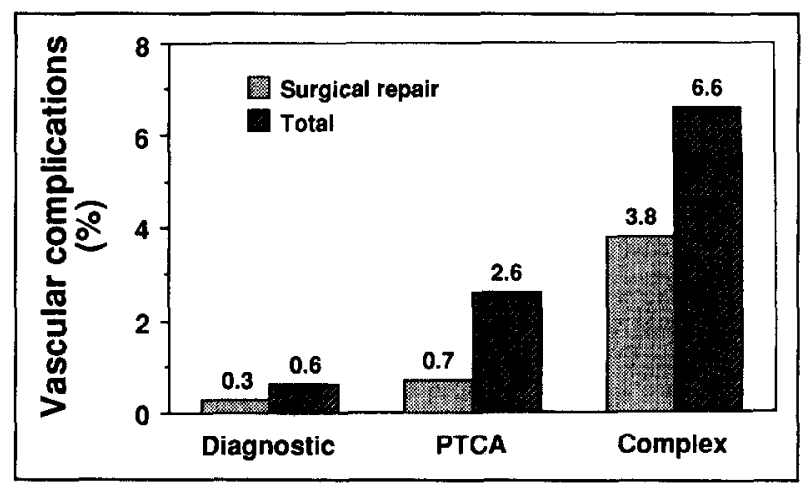

FEURE 1. Comparison of the incldence of access stte complications and need for aurdeal intervention in patients undergoins diegnostic cardiex catheterization, conventional percutaneous trandhemind coronary andoplacty (PTCA), and complex cardiovasculer interventiond procedures. Differences between the groups were highty statiotically significant $(p<0.0001)$. 


\begin{tabular}{|c|c|c|}
\hline Variable & $\begin{array}{c}\text { Complication } \\
(\%) \\
(n=39)\end{array}$ & $\begin{array}{c}\text { No Complications } \\
(\%) \\
(n=150)\end{array}$ \\
\hline \multicolumn{3}{|l|}{ Procedure performed } \\
\hline Diagnostic cardiac catheterization & $6(24)$ & $100(67)$ \\
\hline Coronary angioplasty & $18(46)$ & $38(25)$ \\
\hline Atherectomy & $4(10)$ & $2(1.3)$ \\
\hline Stent & $2(5)$ & $3(2.0)$ \\
\hline Valvuloplasty & $2(5)$ & $3(2.0)$ \\
\hline Intraaortic balloon pump & $2(5)$ & $2(1.3)$ \\
\hline Cardiopulmonary support device & $2(5)$ & $1(0.7)$ \\
\hline \multicolumn{3}{|l|}{$\begin{array}{l}\text { Adjunctive therapy } \\
\text { A }\end{array}$} \\
\hline Preprocedural aspirin & $36(92)$ & $110(73)$ \\
\hline Intraprocedural heparin therapy & $32(83)$ & $53(35)$ \\
\hline Intraprocedural lytic therapy & $11(29)$ & $2(1.3)$ \\
\hline \multicolumn{3}{|l|}{ Procedural details } \\
\hline Arterial sheath size $\geq 8 \mathrm{Fr}$ & $32(82)$ & $56(37)$ \\
\hline Procedure duration $>2$ hours & $17(43)$ & $5(3)$ \\
\hline Sheaths in situ $>24$ hours & $5(14)$ & - \\
\hline
\end{tabular}

and IV). Arterial sheaths with a caliber $\geq 8 \mathrm{Fr}$ were used in $82 \%$ of patients who developed complications compared with $37 \%$ of those without complications ( $p$ $<0.001$ ); arterial sheath sizes $\geq 9 \mathrm{Fr}$ were used in $29 \%$ of patients with arterial complications. Intraprocedural heparin was administered to $83 \%$ of patients with complications compared with $35 \%$ of event-free patients (p <0.001), and fibrinolytic therapy was used in 29 and $1.4 \%$ of patients, respectively $(\mathrm{p}<0.001)$. The preprocedural use of aspirin was also somewhat higher in the complicated group (92 vs $73 \%$ ). In the group with arterial complications, $43 \%$ underwent cardiac catheterization lasting $>2$ hours, and in $14 \%$ the arterial sheaths remained in situ for $>24$ hours because of the periprocedural administration of fibrinolytic therapy or the need for uninterrupted postprocedural anticoagulant therapy.

\section{DISCUSSION}

The principal findings of this study are that the incidence of peripheral arterial complications after complex interventional procedures is significantly higher than after conventional diagnostic and therapeutic procedures. The incidence of complications was most closely associated with the use of large caliber introducing sheaths and the use of periprocedural anticoagulant or fibrinolytic therapy.

Vascular complications after diagnoctic cardiac cathetertzation: Several large, multicenter registries ${ }^{1,2,8,9}$ and single center studies ${ }^{10,11}$ have documented the frequency of vascular complications after diagnostic cardiac catheterization. In studies that have excluded patients aged $<1$ year, the incidence of arterial complications has ranged from 0.2 to $1.9 \%$, depending on the access site. In general, thrombotic ischemic arterial complications have been somewhat higher after procedures performed from the brachial approach than from the femoral route, but the latter approach has been associated with a higher incidence of hemorrhagic complications. $1,2,8-11$ The overall incidence of $0.6 \%$ and the need for surgical repair in $0.3 \%$ in this study is comparable to that noted for femoral vascular access in the larger series.

Dlagnostic procedures versus conventional percutanoous transhminal coronary ansioplasty: The overall incidence of vascular complications after conventional PTCA in this study (2.6\%), and the need for operative arterial repair $(0.7 \%)$, also compare favorably with the frequencies quoted in previous reports. Two single center studies have compared the incidence of local vascular access site complications after diagnostic cardiac catheterization and conventional PTCA. ${ }^{12,13}$ In these studies, coronary angioplasty was not associated with an increased incidence of complications but, in both studies, the frequency of vascular complications after diagnostic procedures was relatively high. In the study of Wyman et al, ${ }^{12}$ surgical repair of the femoral artery was required after $1.6 \%$ of diagnostic procedures compared with $1.5 \%$ after coronary angioplasty, and Kaufman et $\mathrm{al}^{13}$ noted an incidence of vascular complications of $0.9 \%$ after coronary angioplasty compared with $1.2 \%$ after diagnostic procedures. Three other studies have reported the incidence of peripheral vascular complications after PTCA.3,14,15 In the 1977 to 1981 National Heart, Lung, and Blood Institute's PTCA registry of 1,500 patients, ${ }^{3}$ local vascular complications occurred after 1.5\% of the procedures, and in 2 large studies from Emory University, vascular complications occurred after $0.6 \%$ of 3,500 coronary angioplasties performed between 1980 and $1984,{ }^{14}$ and $1 \%$ of 4,988 PTCA procedures performed between 1985 and $1988 .{ }^{15}$ In the latter study, peripheral vascular complications correlated strongly with patient age and the postprocedural use of heparin.

Complex coronary interventional procedures: Over the past 10 years, an increasing number of percutaneous coronary interventions have been performed in patients with unstable coronary syndromes, severe multivessel coronary artery disease, complex coronary lesion morphology, previous coronary artery bypass graft surgery and severely impaired left ventricular function. ${ }^{4}$ In an effort to improve the safety of these high-risk procedures, a variety of new devices have been developed to reduce the likelihood of arterial dissection and abrupt closure, or to provide circulatory support in the event of profound myocardial ischemia and dysfunction. The use of these devices has necessitated the placement of large caliber catheters in peripheral arteries and veins, often in association with intensive anticoagulation or the administration of fibrinolytic therapy. Although previous reports have described the frequency of access site complications occurring after the use of some of these devices, 5,18 no study has previously compared the vascular morbidity of these new procedures with that of conventional coronary interventions.

One of the earliest devices used to increase the safety of conventional PTCA was the intraaortic balloon pump. Several studies have reported an increased incidence of vascular complications and sepsis after the use of these devices. ${ }^{19-22}$ In these studies, the need for vas- 
cular surgical repair ranged from 10.7 to $37 \%$, and correlated with a history of diabetes mellitus, ${ }^{19,21}$ the presence of peripheral vascular disease, ${ }^{19}$ and with prolonged circulatory support ( $>20$ days). ${ }^{20}$ In the current study, the use of intraaortic balloon pumping for highrisk coronary interventions was associated with an incidence of access site complications of only $4.4 \%$. The frequency of complications reported after the use of percutaneous cardiopulmonary support devices has also been high. ${ }^{23,24}$ In 1 single center experience, vascular repair was required after $10 \%$ of procedures in which cardiopulmonary support was used, and $30 \%$ of the patients required blood transfusion. ${ }^{23}$ Vascular morbidity was also high in a report from a multicenter cardiopulmonary support registry ${ }^{24}$; blood transfusion was required in $43 \%$ of 105 patients and significant arterial injury occurred in $26 \%$ of the study group. In the current study, 2 of 10 patients treated with percutaneous cardiopulmonary support required both nonelective vascular surgical repair and blood transfusion.

Relatively little has been published on the frequency of arterial complications after coronary atherectomy or stent implantation. In 1 study, vascular surgical repair was required in $2 \%$ of 67 patients after coronary atherectomy. ${ }^{5}$ After Palmaz-Schatz stent implantation, 10 of 174 patients $(5.7 \%)$ treated with the current intensive anticoagulant regimen required blood transfusion or vascular surgical repair. ${ }^{18}$ In our own experience, although the incidence of access site complications was $8 \%$ in this study, the need for blood transfusion has been as high as $15 \%$ after elective stent implantation. . $^{25}, 26$ This high incidence of bleeding was attributed to excessive anticoagulation with heparin and has fallen considerably since the introduction of more vigorous monitoring of the patients' coagulation status. Aortic balloon valvuloplasty, another procedure requiring the use of large caliber introducing sheaths and balloon catheters, has been associated with major vascular complication rates ranging from 7 to $10 \% 12,27$ and in 1 series $^{28}$ was associated with the need for leg amputation in 3 of 492 $(0.6 \%)$ patients. A similar incidence of complications was noted in this study.

Cilnical implications: In the current study, the strongest predictors of the need for vascular surgical repair, blood transfusion or systemic antibiotic therapy after percutaneous cardiovascular interventional procedures were the size of the arterial catheters, and the use of anticoagulant or fibrinolytic therapy. Patient age and the presence of peripheral vascular disease were also important variables, but patient gender, individual risk factors for coronary artery disease, obesity and the extent of coronary disease did not appear to be important factors. These findings suggest that the incidence of vascular complications might be reduced by further technical refinements such as a reduction in device caliber. In recent years, the caliber of directional coronary atherectomy catheters, intraaortic balloon pumps and the arterial and venous catheters of the percutaneous cardiopulmonary support device have all been effectively reduced. Furthermore, a reduction in the profile of both fixed-wire and over-the-wire balloon angioplasty systems has permitted an increasing number of coronary angioplasties to be performed through 6 and 7Fr guiding catheters. ${ }^{29}$ Efforts to reduce the thrombogenicity of metallic stents are also clearly warranted so that the need for intensive antiplatelet and antithrombotic therapy may be reduced. Finally, although less predictive of the likelihood of complications, patient selection remains an important consideration, particularly in the choice of 2 procedures of apparently equivalent efficacy in elderly patients or those with overt peripheral vascular disease.

Study limitations: The relatively small number of access site complications in this study limits the number of clinical and procedural variables that can be legitimately evaluated as predictive factors. Similarly, the low event rate does not permit any direct comparison of the likelihood of complications after the respective coronary interventional procedures. Finally, multivariable regression analysis was not performed; the variables identified by univariate analysis may thus be interrelated.

\section{REFERENCES}

1. Kennedy JW, The Registry Committee of the Society for Cardiac Angiography. Symposium on catheterization complications: complications associated with cardiac catheterization and angiography. Cathet Cardiovasc Diagn 1982;8:5-11. 2. Johnson LW, Lozner EC, Johnson S, Krone R, Pichard AD, Vetrovec GW Noto TJ. Coronary arteriography 1984-1987: a report of the Registry of the Society for Cardiac Angiography and Interventions. 1. Results and complications. Cathet Cardiovasc Diag 1989;17:5-10.

3. Dorros G, Cowley MJ, Simpson J, Bentivoglio LG, Block PC, Bourassa M Detre K, Gosselin AJ, Gruntzig AR, Kelsey SF, Kent KM, Mock MB, Mullin SM, Myler RK, Passamani ER, Stertzer SH, Williams DO. Percutaneous transluminal coronary angioplasty: report of complications from the National Heart, Lung and Blood Institute PTCA Registry. Circulation 1983;67:723-9.

4. Detre K, Ilolubkov R, Kelsey S, Bourassa M, Williams D, Ilolmes D, Dorros G, Faxon D, Myler R, Kent K, Cowley M, Cannon R, Robertson T. One year follow-up results of the 1985-1986 National Heart, Lung, and Blood Institute's Percutaneous Transluminal Coronary Angioplasty Registry. Circulation 1989;80 421-428.

5. Safian RD, Gelbfish JS, Erny RE, Schnitt SJ, Schmidt DA, Baim DS. Coronary atherectomy: clinical, angiographic, and histological findings and observations regarding potential mechanisms. Circulation 1990;82:69-79.

6. Muller DWM, Ellis SG. Advances in coronary angioplasty: endovascular stents. Coronary Artery Disease 1990;1:438-448.

7. Shawl FA, Domanski MJ, Wish MH, Davis M. Percutaneous cardiopulmonary bypass support in the catheterization laboratory: technique and complications. Am Heart J 1990;120:195-203.

8. Adams DF, Fraser DB, Abrams HL. The complications of coronary arteriography. Circulation 1973;48:609-618.

9. Davis K, Kennedy JW, Kemp HG, Judkins MP, Gosselin AS, Killip T. Complications of coronary arteriography from the collaborative study of Coronary Artery Surgery (CASS). Circulation 1979;59:1105-1111.

10. Miller GAH. Local arterial complications of left heart catheterisation. $J$ Royal College of Physicians 1986;20:288-289.

11. Babu SC, Piccorelli GO, Shah PM, Stein JH, Clauss RH. Incidence and results of arterial complications among 16,350 patients undergoing cardiac catheterization. I Vasc Surg 1989;10:113-116.

12. Wyman RM, Safian RD, Portway V, Skillman JJ, McKay RG, Baim DS Current complications of diagnostic and therapeutic cardiac catheterization. $J$ Am Coll Cardiol 1988;12:1400-1406.

13. Kaufman J, Moglia R, Lacy C, Dinerstein C, Moretra A. Peripheral vascular complications from percutaneous transluminal coronary angioplasty: a comparison with transfemoral cardiac catheterization. Am J Med Sci 1989;297:22-25. 14. Bredlow CE, Roubin GS, Leimgruber PP, Douglas JS, King SB, Gruentzig AR. In-hospital morbidity and mortality in patients undergoing elective coronary angioplasty. Circulation 1985;72:1044-1052.

15. Oweida SW, Roubin GS, Smith RB, Salam AA. Pustcatheterization vascular complications associated with percutaneous transluminal coronary angioplasty. $J$ Vasc Surg 1990;12:310-315.

16. Sheikh KH, Adams DB, McCann R, Lyerly HK, Sabiston DC, Kisslo J. 
Utility of Doppler color flow imaging for identification of femoral arterial complications of cardiac catheterization. Am Heart $J$ 1989;117:623-628.

17. Messina LM, Brothers TE, Wakefield TW, Zelenock GB, Lindenauer SM, Greenfield LJ, Jacobs LA, Fellows EP, Grube SV, Stanley JC. Clinical characteristics and surgical management of vascular complications in patients undergoing cardiac catheterization: interventional versus diagnostic procedures. $J$ Vasc Surg 1991;13:593-600.

18. Schatz RA, Baim DS, Leon M, Ellis SG, Goldberg S, Hirshfeld JW, Cleman MW, Cabin HS, Walker C, Stagg J, Buchbinder M, Teirstein PS, Topol EJ, Savage M, Pcrez JA, Curry RC, Whitworth H, Sousa E, Tio F, Almagor Y, Ponder R, Penn IM, Leonard B, Levine SL, Fish D, Palmaz JC. Clinical experience with the Palmaz-Schatz coronary stent: initial results of a multicenter study. Circulation 1991:83:148-161.

19. Alderman JD, Gabliani GI, McCabe CH, Brewer CC, Lorell BH, Pasternak PC, Skillman JJ, Steer ML, Baim DS. Incidence and management of limb ischemia with percutaneous wire-guided intraaortic balloon catheters. J Am Coll Cardiol 1987;9:524-530.

20. Freed PS, Wasfie T, Zado B, Kantrowitz A. Intraaortic balloon pumping for prolonged circulatory support. Am J Cardiol 1988;61:554-557.

21. Wasfie T, Freed PS, Rubenfire M, Wajszczuk W, Reimann P, Brozyna W, Schork MA, Kozlowski J, Kantrowitz A. Risks associated with intraaortic balloon pumping in patients with and without diabetes mellitus. $A m J$ Cardiol 1988;61: $558-562$

22. Kahn JK, Rutherford BD, McConahay DR, Johnson WL, Giorgi LV,
Hartzler GO. Supported "high risk" coronary angioplasty using intraaortic balloon pump counterpulsation. J Am Coll Cardiol 1990;15:1151-1155.

23. Shawl FA, Domanski MJ, Wish MH, Davis M. Percutaneous cardiopulmonary bypass support in the catheterization laboratory: technique and complications. Am Heart J 1990;120:195-203

24. Vogel RA, Shawl F, Tommaso C, O'Neill W, Overlie P, O'Toole J, Vandormael M, Topol E Tabari K, Vogel J, Smith S, Freedmann R, White C, George B, Teirstein P. Initial report of the National Registry of Elective Cardiopulmonary Bypass Supported Coronary Angioplasty. J Am Coll Cardiol 1990;15:23-29. 25. Dick RJ, Popma JJ, Muller DWM, Burek KA, Topol EJ. In-hospital costs associated with new percutaneous coronary devices. Am J Cardiol 1991;68: 879-885.

26. Ver Lee PN, Muller DWM, Popma JJ, Ellis SG, Topol EJ. Coronary stenting for abrupt closure vs elective stenting for refractory restenosis: clinical and quantitative angiographic outcomes (abstr). J Am Coll Cardiol 1991;17:280A

27. Safian RD, Berman AD, Diver DJ, McKay LL, Come PC, Riley MF, Warren SE, Cunningham MJ, Wyman M, Weinstein JS, Grossman W, McKay RG. Balloon aortic valvuloplasty in 170 consecutive patients. $N$ Engl $J$ Med 1988;319:125-130.

28. Isner JM, and the Mansfield Scientific Aortic Valvuloplasty Registry Investigators. Acute catastrophic complications of balloon aortic valvuloplasty. J Am Coll Cardiol 1991;17:1436-1444.

29. Feldman R, Glemser E, Kaizer J, Standley M. Coronary angioplasty using new 6 French guiding catheters. Cathet Cardiovasc Diag 1991;23:93-99. 